\title{
The Modulation of Tropical Cyclone Activity in the Australian Region by the Madden-Julian Oscillation
}

\author{
JONTY D. HALL* \\ Department of Mathematics and Statistics, Monash University, Melbourne, Australia \\ AdRian J. MATtheWs \\ University of East Anglia, Norwich, United Kingdom \\ DAVID J. KAROLY \\ Department of Mathematics and Statistics, Monash University, Melbourne, Australia
}

(Manuscript received 18 January 2001, in final form 13 June 2001)

\begin{abstract}
The observed relationship between tropical cyclone activity in the Australian region and the Madden-Julian oscillation (MJO) has been examined using $20 \mathrm{yr}$ of outgoing longwave radiation, NCEP-NCAR reanalysis, and best track tropical cyclone data. The MJO strongly modulates the climatological pattern of cyclogenesis in the Australian region, where significantly more (fewer) cyclones form in the active (inactive) phase of the MJO. This modulation is more pronounced to the northwest of Australia. The relationship between tropical cyclone activity and the MJO was strengthened during El Niño periods. Variations of the large-scale dynamical conditions necessary for cyclogenesis were explored, and it was found that MJO-induced perturbations of these parameters correspond with the observed variation in cyclone activity. In particular, $850-\mathrm{hPa}$ relative vorticity anomalies attributable to the MJO were found to be an excellent diagnostic of the changes in the large-scale cyclogenesis patterns.
\end{abstract}

\section{Introduction}

A climatology of tropical cyclone (TC) incidence in the Australian region (Fig. 1) indicates that virtually the entire northern half of the Australian coastline is susceptible to the destructive effects of landfalling TCs. More complete climatologies may be found in McBride and Keenan (1982) and Holland (1984), but a few points are worthy of note. There are two main regions of cyclogenesis, a western region over the eastern Indian Ocean and the Timor Sea, and an eastern region over the Coral Sea. The peak in activity around the east coast is important, as this is the most developed region of tropical Australia, and is also one of the fastest developing areas of the country. Cyclones off the west coast tend to be more intense than their eastern counterparts (Holland 1984), and although the coast is very sparsely lia.

* Current affiliation: Bureau of Meteorology, Melbourne, Austra-

Corresponding author address: Dr. Adrian Matthews, School of Environmental Sciences, University of East Anglia, Norwich NR4 7TJ, United Kingdom.

E-mail: a.j.matthews@uea.ac.uk settled, much industry is located in this region. The origins of the vast majority of TCs in the Australian region can be found in the vicinity of the intertropical convergence zone (ITCZ). McBride and Keenan (1982) estimate that some $85 \%$ of cyclones in the Australian region have their genesis locations near the ITCZ. As the ITCZ is located near or over the continent for the majority of the cyclone season, a large proportion of TCs in the Australian basin form in close proximity to the mainland coast. McBride and Keenan (1982) found that about half of all cyclones in their study formed within $300 \mathrm{~km}$ of land - a situation unique to the Australian basin.

As organized preparations for a TC impact can lead to dramatic reductions in loss of life and destruction, there are obvious benefits associated with the ability to accurately predict the occurrence of a landfalling cyclone. The majority of the work conducted in this area has concentrated on short lead times, out to about 3 days. At these shortest lead times there have been considerable advances in cyclone motion forecasting (Davidson and Weber 2000), primarily through vast improvements in dynamical model guidance. Beyond this timescale, the buildup of errors stemming from impre- 


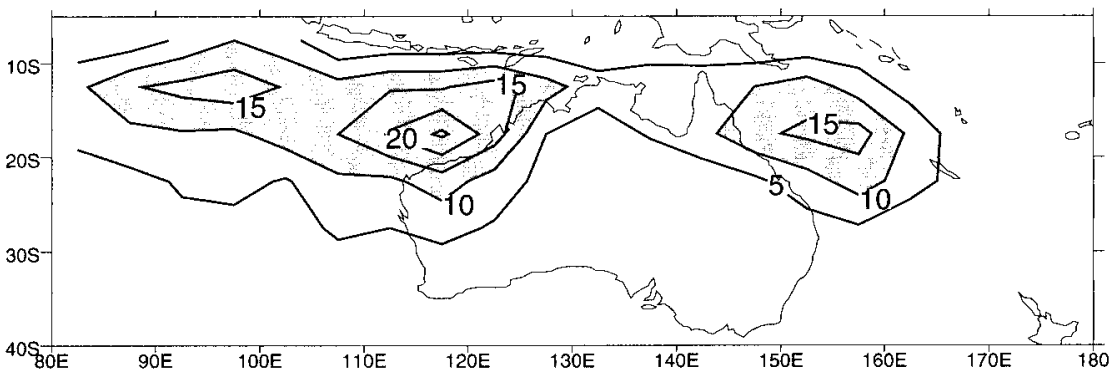

FIG. 1. Average decadal occurrence of tropical cyclones within $5^{\circ} \times 5^{\circ}$ lat-lon squares, for the period Jul 1974-Jun 1996. Contour interval is 5 cyclones per decade and values above 10 cyclones per decade are shaded.

cise initialization and the inherent chaotic nature of the atmosphere leads to a rapid decrease in the skill of these models, and forecasts based upon climatology alone become superior. The situation with TC formation is even more problematic. In this case, mechanisms such as complex scale interactions, processes at the air-sea interface, and diabatic heating profiles - all of which must be parameterized in current dynamical models-become critical and dominant factors. Accordingly, there is little skill involved in this aspect of forecasting.

Although the short lead time guidance is vital in the interests of saving lives, there is no doubt that guidance of expected TC activity 5-20 days in the future would be a valuable asset. This is particularly true in the Australian region, where cyclone formation close to the coasts can lead to rapidly developing threats. In these situations a level of preparation prior to the storm's development is important, as there is often insufficient time once the storm has been identified. As dynamical prediction models do not currently provide much guidance at these lead times, a different approach is required. One possibility is through the establishment of relationships between long-period oscillations of the atmosphere and TC numbers.

The state of the El Niño-Southern Oscillation (ENSO) has been related to TC numbers in many regions of the world (e.g., Solow and Nicholls 1990; Evans and Allen 1992). Coherent relationships between cyclone occurrence and the phase of ENSO have been found, although the dynamical reasons for the modulation appear to be quite different in the various cyclone basins of the world. For example, in the eastern Australian region, the reduction of TC activity during the El Niño phase is primarily due to the displacement of the warm sea surface temperatures and regions of low surface pressure to the east. In contrast, a similar reduction in the Atlantic has been attributed to an increase in upper-tropospheric westerly winds during El Niño (Gray et al. 1993). In the Atlantic basin, quantitative guidance on the likely level of hurricane activity is routinely provided to the public between 6 and 11 months before the season begins (Landsea et al. 1994; Gray et al. 1992). These forecasts are primarily based on the phase of ENSO and the stratospheric quasi-biennial os- cillation (QBO), and probably represent the first definite use of low-frequency mechanisms to longer lead time forecasting of TCs. In the Australian region, the QBO does not appear to be an important factor (Gray and Sheaffer 1989). Not surprisingly, much of the current work is directed toward better forecasting of the ENSO mechanism.

Less work has been undertaken on the modulation of TCs at the intraseasonal timescale. Yet for many years there has been abundant evidence that TC formation is strongly modulated at these timescales as well. Gray (1979) studied each of the world's TC basins, and found that the formation of TCs is not evenly distributed in time within any particular season. Rather, cyclogenesis appears to occur in clusters. Periods of 1 or 2 weeks of active formation may produce as many as 10 cyclones, whereas the inactive periods of similar length may see no cyclones forming at all. In the Australian region, this approximately 30-50-day period strongly suggests some form of connection with the Madden-Julian oscillation (MJO), which is the dominant mode of oscillation of the tropical troposphere at this timescale (Madden and Julian 1994 present a comprehensive review). The MJO can be summarized as an eastward-propagating disturbance of the tropical troposphere with zonal wavenumber 1 . It exerts an influence on many aspects of the tropical flow, including temperature, moisture, sea level pressure, and both the rotational and divergent parts of the wind field. In the Eastern Hemisphere, it also interacts strongly with deep convection, with enhanced convective activity at all scales in the "wet" phase, and correspondingly suppressed convection in the "dry" phase (Hendon and Liebmann 1994). A distinct hierarchy of convective organization has been observed within the active phase of the MJO, with eastward-propagating supercloud clusters with diameters of the order of $3000 \mathrm{~km}$ forming an envelope of enhanced mesoscale cloud cluster activity (Nakazawa 1988; Hendon and Liebmann 1994). As all TCs are initially formed from these cloud clusters, the modulation of activity during MJO passage is likely to be an important factor to cyclogenesis. However, the effect of the MJO on the dynamical parameters may also have an important role to play. 
(a) EOF1

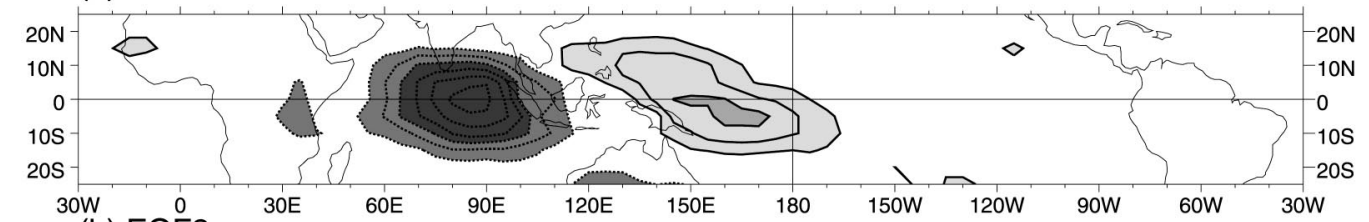

(b) EOF2

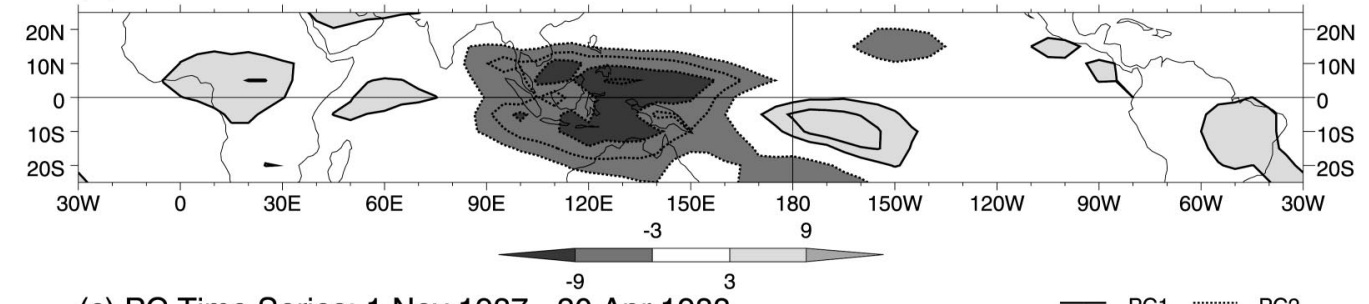

(c) PC Time Series: 1 Nov $1987-30$ Apr 1988

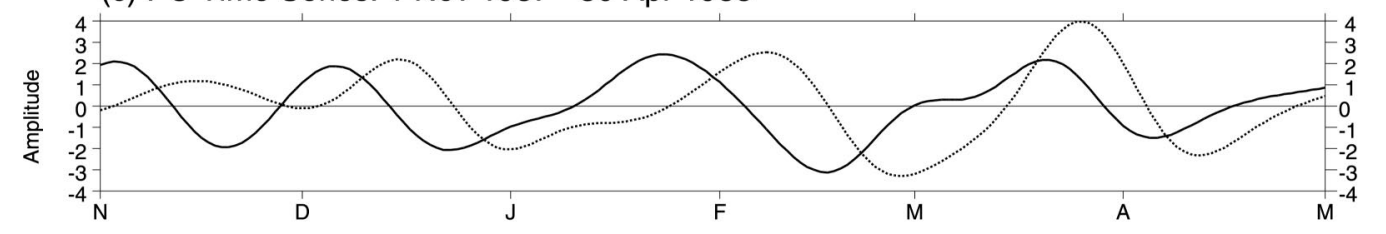

(d) Z: Phase, Amplitude (41-day running mean): 1 Nov 1987 - 30 Apr 1988

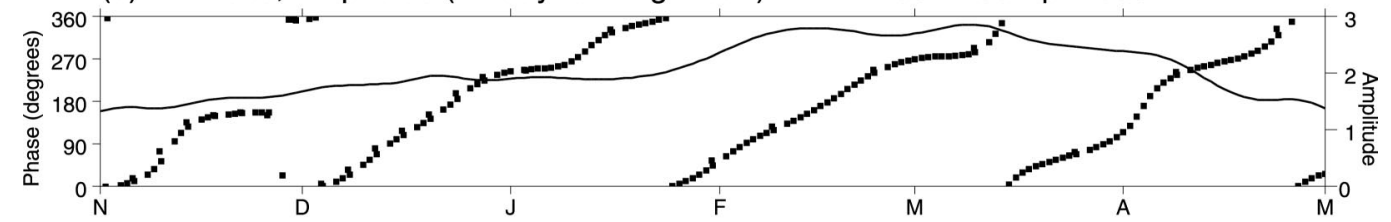

(e) Z: 1 Nov 1987 - 30 Apr 1988

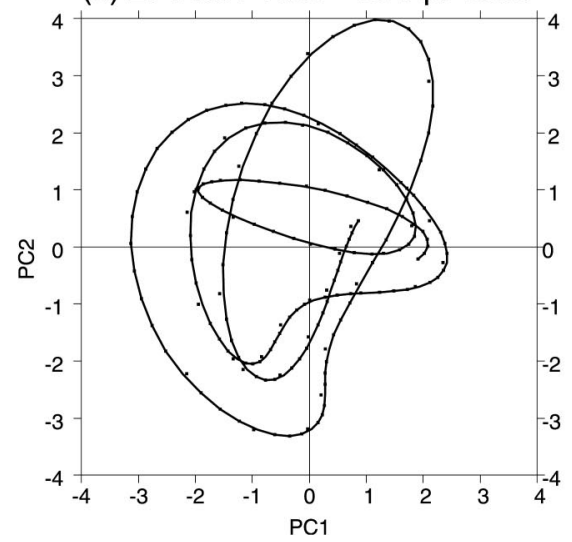

FIG. 2. Empirical orthogonal function analysis of 20-200-day filtered OLR: (a) EOF 1, (b) EOF 2; contour interval is $3 \mathrm{~W} \mathrm{~m}^{-2}$; the zero contour is omitted; shading is shown by the legend. (c) PC 1 (solid line) and PC 2 (dotted line) from 1 Nov 1987 to 30 Apr 1988. (d) Phase $\alpha$ (dots; scale on left-hand axis) and 41-day running mean of amplitude $A$ (solid line; scale on right-hand axis) of $\mathbf{Z}$ from 1 Nov 1987 to 30 Apr 1988; (e) $\mathbf{Z}$ plotted from 1 Nov 1987 to 30 Apr 1988.

Forecasters are aware of intraseasonal variability in TC activity associated with the MJO, and do take this into account subjectively (e.g., Hanstrum et al. 1999). However, little quantitative research has been undertaken into the relationship. Von Storch and Smallegange (1991) found significant modulation of TC numbers in the North and South Pacific Oceans by the MJO, utilizing a 5-yr dataset, and defining the MJO using sat- ellite observations of outgoing longwave radiation (OLR). Liebmann et al. (1994) also found increases and decreases in TC activity that appeared to be consistent with the phase of the MJO. They attributed this result to the increase in meso- and synoptic-scale convective activity brought about by the MJO (Hendon and Liebmann 1994), and the associated low-level cyclonic relative vorticity and convergence anomalies. More re- 
cently, Maloney and Hartmann (2000) found significant modulation of eastern North Pacific hurricane numbers and intensities by the MJO. As the MJO has little direct effect on deep convection in this region, their results appear to emphasize the importance of the forcing of large-scale dynamical fields by the eastward-propagating MJO.

The aims of this study are to continue these investigations into the modulation of $\mathrm{TC}$ formation by the MJO, with particular emphasis on the Australian region. Although the major focus is on cyclogenesis, preliminary investigations into the motion and intensity of the cyclones are also made. Earlier studies have been somewhat restricted by the brevity of the datasets used, which led to contaminations of the signal by, for example, ENSO (von Storch and Smallengange 1991). In the present study, an observational, compositing approach is adopted, based on $20 \mathrm{yr}$ of data. A particular goal of the study is to select an optimum temporal resolution of the MJO to allow these TC genesis patterns to be observed, while ensuring that the MJO evolution is slow enough to set a basic state for cyclogenesis. If the current intense research into the MJO produces techniques to improve its prediction, then such a relationship would have obvious benefits to medium-range forecasting of TCs.

\section{Data and methodology}

\section{a. Datasets}

The best track TC dataset was obtained from the Australian Bureau of Meteorology. This dataset includes all "significant" TCs that formed, or moved into, the Southern Hemisphere sector between $80^{\circ}$ and $170^{\circ} \mathrm{E}$. Significant in this case is taken to mean any system reaching tropical depression status (containing estimated 10-min sustained winds greater than $17 \mathrm{~m} \mathrm{~s}^{-1}$ ). Satellite-derived estimates of central pressure, and latitude and longitude of the center of each system were included. The central pressure estimates were based on the Dvorak technique (Dvorak 1984). The majority of location estimates were also derived from satellite imagery, giving an accuracy of approximately $50-100 \mathrm{~km}$, although this may be somewhat worse in the case of weak systems. Smaller deviations from the mean path than this were removed in the best track production process. Some of the position estimates are supplemented by radar imagery providing increased resolution; however, for the purposes of this study, the satellite estimates are adequate. Most of the estimates are at 6hourly intervals, although in some cases 3-hourly reports are available, while in some of the weak or developing systems only 12-hourly data have been recorded.

OLR data were produced by National Oceanic and Atmospheric Administration (NOAA) polar orbiting satellites (Leibmann and Smith 1996). The OLR data were obtained for the period November 1974 to April 1998, except for 16 March 1976 to 31 December 1978 for which no data were available. Wind field reanalysis datasets from the National Centers for Environmental Prediction-National Center for Atmospheric Research (NCEP-NCAR) (Kalnay et al. 1996) were retrieved for a similar period. Both datasets were obtained as daily means, interpolated onto a $2.5^{\circ} \times 2.5^{\circ}$ latitude-longitude grid.

\section{b. Determination of the MJO basic state}

Following Matthews (2000), the state of the MJO on any given day was defined by the two leading empirical orthogonal functions (EOFs) of 20-200-day filtered tropical OLR data. EOF 1 shows the familiar MJO convective dipole, with negative OLR anomalies corresponding to enhanced convection, over the Indian Ocean, and positive OLR anomalies corresponding to reduced convection, over the western Pacific (Fig. 2a). EOF 2 shows enhanced convection over the Indonesian sector and along the South Pacific convergence zone, and areas of reduced convection over Africa, the central Pacific, and South America (Fig. 2b).

During a period of MJO activity, the principal component time series of EOF $1[\mathrm{PC} 1(t)]$ leads the corresponding time series for $\mathrm{EOF} 2[\mathrm{PC} 2(t)]$ by a quarter of an MJO cycle (approximately 12 days), corresponding to eastward movement of the convective anomalies over the warm pool region. For example, the MJO activity for the 1987-88 tropical cyclone season is shown in Fig. 2c. Three successive MJO events occurred simultaneously from the beginning of December 1987 to the end of March 1988 (Matthews et al. 1996), as evidenced by the large amplitudes of PC1 and PC2 with PC1 leading PC2 by a quarter cycle. Following Matthews (2000), the MJO can be represented by the vector $\mathbf{Z}$ in a two-dimensional phase space defined by these two PCs:

$$
\mathbf{Z}(t)=[\operatorname{PC} 1(t), \operatorname{PC} 2(t)]
$$

The amplitude of the MJO is then given by

$$
A(t)=\left[\mathrm{PC}^{2}(t)+\mathrm{PC}^{2}(t)\right]^{1 / 2}
$$

and the phase by

$$
\alpha(t)=\tan ^{-1}[\mathrm{PC} 2(t) / \mathrm{PC} 1(t)] .
$$

The amplitude (passed through a 41-day running mean) and phase during the 1987-88 season are shown in Fig. $2 \mathrm{~d}$. The amplitude is high throughout the period of strong MJO activity and the phase steadily increases with time, indicating eastward propagation of the convective anomalies. However, during November 1987 the amplitude is relatively low and the phase exhibits a period of stagnation then a discontinuity, indicating little or no MJO activity. Other periods of MJO inactivity (not shown) are characterized by low running mean amplitude (RMA) and sporadic phase behavior (either in- 
creasing or decreasing with time, but showing no overall increasing trend).

This amplitude and phase behavior can be alternatively shown in a phase-space diagram of the MJO vector $\mathbf{Z}$ (Fig. 2e). The time evolution of $\mathbf{Z}$ follows a counterclockwise rotation about the origin during periods of MJO activity. For the purposes of the current study, the MJO was divided into four categories labeled A, B, C, and $\mathrm{D}$, each covering a quarter of the MJO cycle. Category A was initially defined as those times when the phase of the MJO was in the quarter cycle centered on $\alpha=0^{\circ}$ (Fig. 2e), that is, around the time when PC1 is a maximum. Similarly, categories B, C, and D were initially defined as the times when the phase was in the quarter cycles centered on $\alpha=90^{\circ}, 180^{\circ}$, and $270^{\circ}$, respectively, and correspond to the times around when PC2 is a maximum, PC1 is a minimum and PC2 is a minimum, respectively.

A further criterion for a day to fall in one of these categories was that the RMA on that day must exceed a threshold value. The standard deviation of the RMA was normalized to have unit amplitude, and this value was taken as the initial threshold. A final criterion for a day to be included in category A-D was that the phase $\alpha$ must be increasing with time on that day, indicating eastward propagation of the convective anomalies. In general, it was found that if the amplitude criterion had been met, then this phase criterion was almost always satisfied anyway. All days that did not meet either the amplitude or phase criteria were assigned to a separate category (NONE), representing a control sample of days when there was deemed to be no MJO activity.

As the period of the MJO is approximately 40-50 days, each category will be of the order of 10-12 days long. This can be considered long enough to provide a basic environmental state to which the formation of TCs can be related. Several conflicting factors affected the choice of number of MJO categories. If the difference in TC characteristics (genesis region, cyclone tracks) between the MJO categories are due to the change in the basic state between the categories, then the basic state (climatological mean plus MJO anomaly) must remain essentially constant throughout the category. This imposes a maximum temporal length for each category of about a quarter of the period of the MJO (approximately 12 days). However, in order to look at the behavior of cyclones within a category, the category should last at least as long as the lifetime of a TC-in the Australian region the mean lifetime is about 7 days (McBride and Keenan 1982). Also, due to the finite length of the dataset, each category should be long enough to have sufficient TCs occurring within it for statistically significant conclusions to be made. A further constraint on the minimum category length is that it should be large compared to the period over which the cyclogenesis process takes place. McBride and Keenan (1982) found this to be about 1-2 days in the eastern Australian region, and 2-4 days off western
Australia. The choice of 12 days per category, and, therefore, four categories per MJO life cycle, is a compromise between these constraints.

The OLR patterns corresponding to the four MJO categories are shown in Fig. 3. These are constructed by regressing gridpoint OLR time series onto the PC1 and PC2 time series. A negative OLR anomaly, corresponding to a region of enhanced convection, moves eastward from the Indian Ocean in category A (Fig. 3a), over the Indonesian-Australian sector in category B (Fig. 3b), and the western Pacific in category $\mathrm{C}$ (Fig. $3 c)$, before decaying east of the date line in category $D$ (Fig. 3d). Positive OLR anomalies, indicating reduced convection, lie ahead of and behind the region of enhanced convection. A full description of the methodology and description of the MJO cycle using this technique is given by Matthews (2000).

\section{c. Tropical cyclone binning procedure}

We now consider the modulation of TC genesis in the different MJO phases. Individual TCs were allocated to one of the five MJO categories described in section $2 \mathrm{~b}$ above. The category of each cyclone was determined by the phase of the MJO at the time the cyclone formed. This procedure requires further explanation as cyclogenesis is not a sharply defined event, and there are several definitions of when a disturbance becomes a TC. The most frequently adopted definition (e.g., Frank 1982) is that genesis has occurred when a mesoscale vortex has formed within the cloud cluster, and the system has become self-sustaining, no longer requiring external forcing for its existence. However, the adoption of this methodology introduces the new problem of determining this event from satellite imagery alone.

In order to assess the magnitude of these problems, the binning analysis was performed using two different definitions of cyclogenesis. In the first method, the first noted record of each system in the best track dataset was taken as the genesis point. Using the alternate definition, genesis was taken to have occurred when a system reached an estimated central pressure (ECP) of 995 $\mathrm{hPa}$. This is probably slightly lower than a value consistent with the definition of genesis given by Frank, but it does have the advantage of allowing the inclusion of most of the systems in the dataset. Cyclones that had formed outside of the domain, and subsequently entered it, were also removed from both analyses. This turned out to be a very rare occurrence-only 8 of the 233 systems included in the study were eliminated in this way, all entering the domain from east of $170^{\circ} \mathrm{E}$. The differences between the results obtained using the two methodologies were minor, the main one being that 21 weak cyclones were omitted from the second analysis as they did not reach an intensity of $995 \mathrm{hPa}$. The proportion of cyclones in each category was virtually unchanged, suggesting that the ill-defined period over which cyclogenesis occurs is short compared to the 
(a) Category A

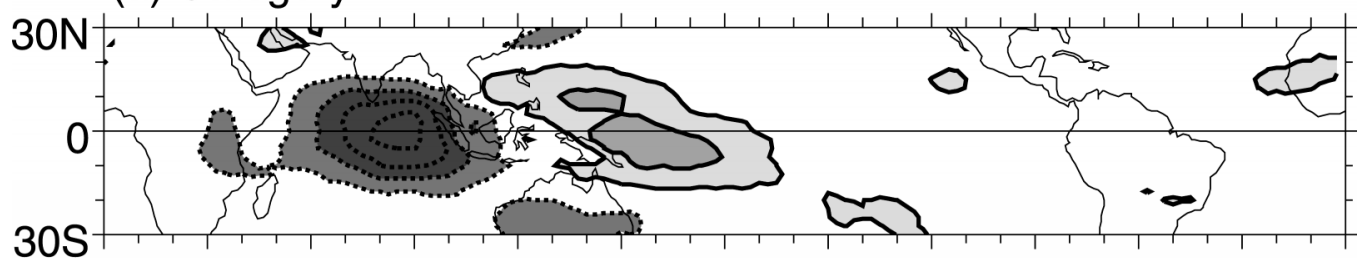

(b) Category B

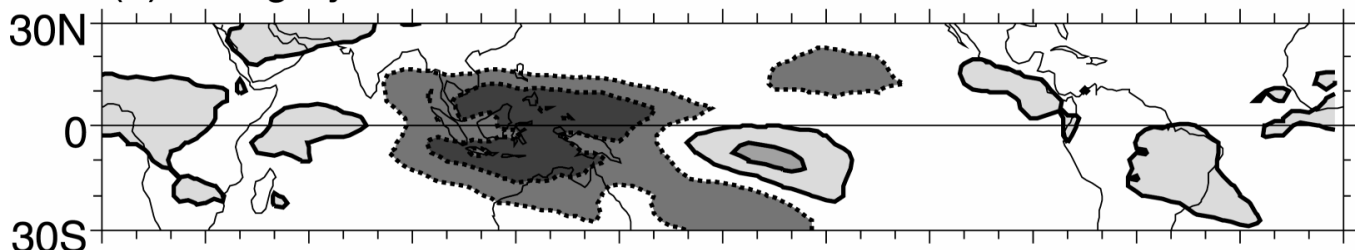

(c) Category C

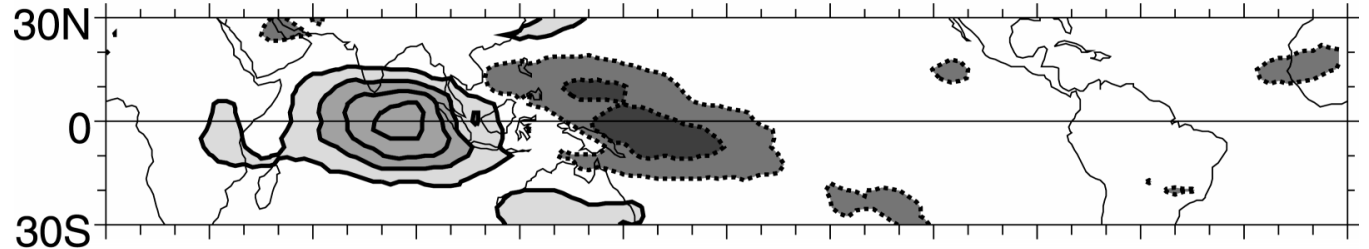

(d) Category D
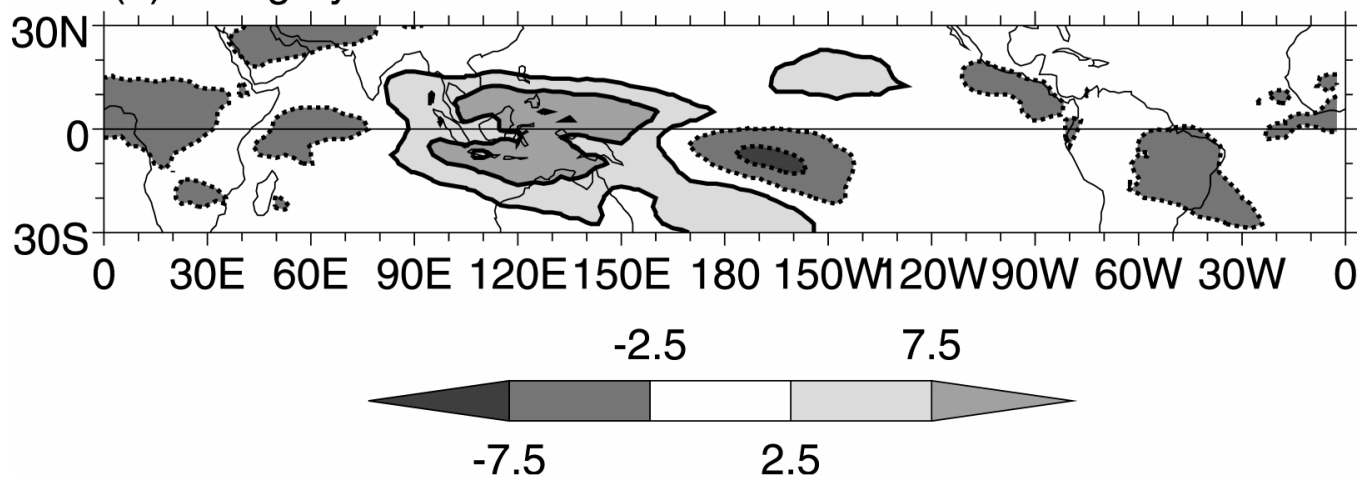

FIG. 3. Anomaly maps of OLR for MJO category (a) A, (b) B, (c) C, and (d) D. Contour interval is $5 \mathrm{~W} \mathrm{~m}^{-2}$; negative contours are dotted; first positive contour is at $2.5 \mathrm{~W} \mathrm{~m}^{-2}$; shading is indicated by the legend.

length of the MJO categories. This also justifies the decision to retain four categories of the MJO. For the remainder of this study, the $995-\mathrm{hPa}$ ECP threshold method of cyclone binning was adopted.

A statistical test was performed on the distribution of cyclone numbers in each MJO category, with a null hypothesis that the cyclones were uniformly distributed. It was assumed that the probability of cyclogenesis occuring on any particular day was fixed, leading to a binomial distribution. The relevant statistic is

$$
Z=\frac{\hat{p}-p_{0}}{s_{\hat{p}}},
$$

where $p_{0}$ and $\hat{p}$ are the expected and observed proportion of cyclogenesis days within a particular MJO category, respectively, and $s_{\hat{p}}=\sqrt{p_{0}\left(1-p_{0}\right) / N}$ is an estimator of the standard deviation of the fraction of cyclogenesis days, where $N$ is the number of days in the category. The test statistic $Z$ follows a Gaussian distribution with zero mean and unit standard deviation. It was tested at the $90 \%$ and $95 \%$ levels, using a two-tailed test, with critical values of $Z= \pm 1.64$ and $Z= \pm 1.96$, respectively.

\section{Tropical cyclone formation \\ a. Modulation of tropical cyclone activity}

The genesis locations of the TCs in each category are shown in Fig. 4 and the cyclone tracks are shown in Fig. 5. The genesis locations and number of days in each category are summarized in Table 1, where the domain has been divided into a western region (west of $135^{\circ} \mathrm{E}$ ) and an eastern region (east of $135^{\circ} \mathrm{E}$ ), which approximately divides the two regions of mean peak 
(a) Category $A$

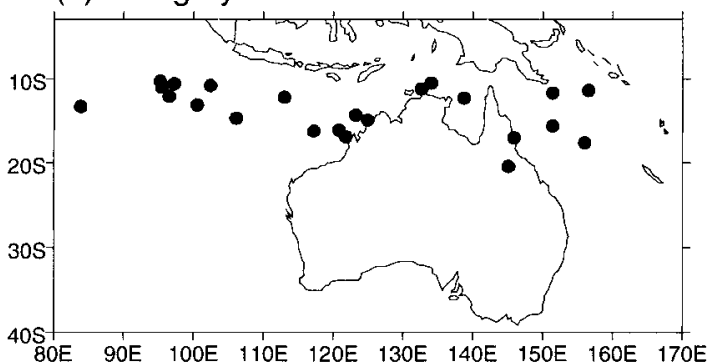

(b) Category B

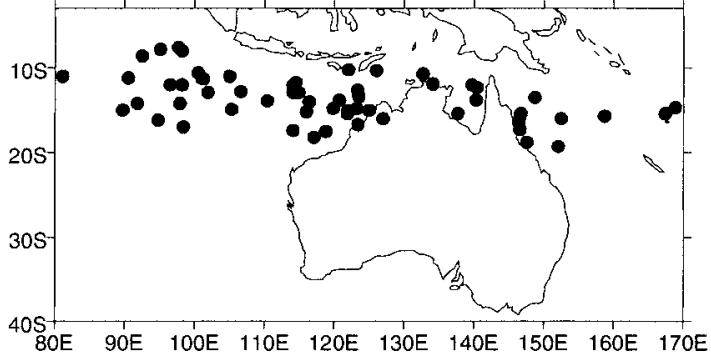

(c) Category $\mathrm{C}$

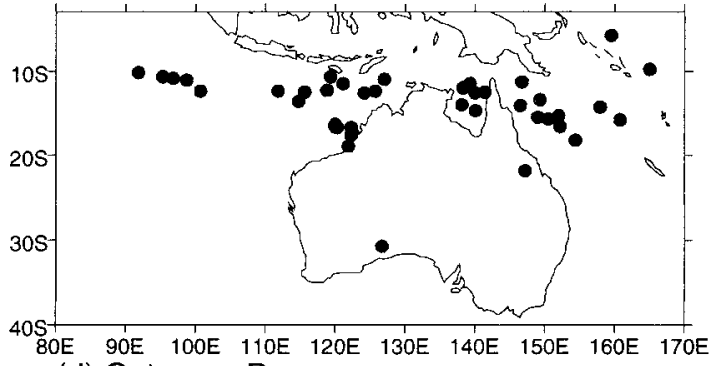

(d) Category D

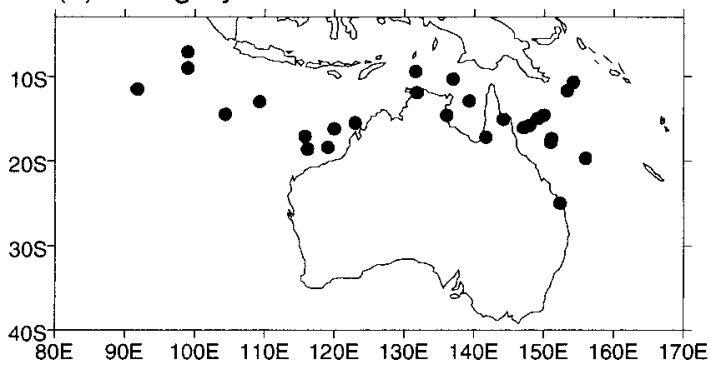

(e) Category NONE

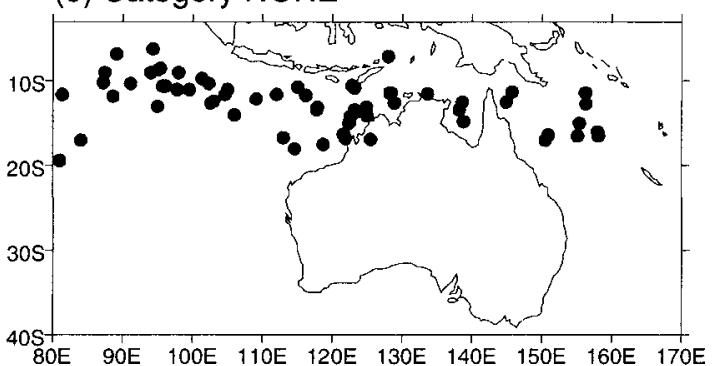

FIG. 4. Tropical cyclone genesis locations for MJO category (a) A, (b) B, (c) C, (d) D, and (e) NONE.
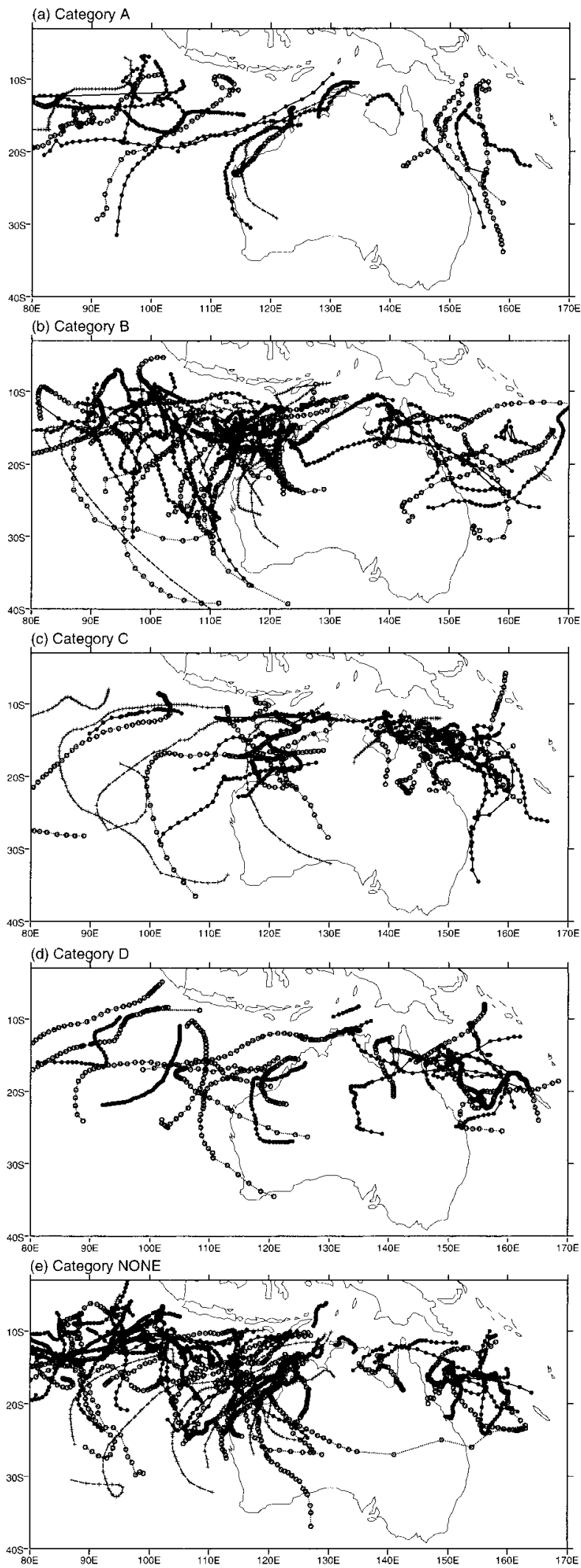
cyclone activity (Fig. 1). In the western region, there were 142 cyclogenesis days, which is $3.7 \%$ of the total of 3865 days (Table 1). Under the null hypothesis that the cyclones are uniformly distributed between the MJO categories, then $p_{0}=3.7 \%$. For the eastern region, there were 70 cyclogenesis days, and $p_{0}=1.8 \%$.

In category A (Figs. 4a, 5a), much of the activity in the western region has been displaced to the west of the climatological peak near the western coast of Australia (Fig. 1). Only 16 cyclones formed in the western region (Table 1), representing $\hat{p}=2.4 \%$ of the $N=675$ days in this category. The test statistic has the value $Z=$ -1.80 . Hence, at the $90 \%$ level, significantly fewer cyclones occurred in the western region during category A, compared to climatology. In the eastern region, only seven cyclones formed during the entire $20-y$ r period, although this was not a statistically significant reduction. This is consistent with the MJO basic state for this category (Fig. 3a) with enhanced convection over the central Indian Ocean and reduced convection over the Australian sector and the western Pacific. Two cyclones appear to form over the land, over Queensland (Fig. 4a). However, this is due to the $995-\mathrm{hPa}$ threshold definition of TC formation that has been used; inspection of the complete cyclone tracks (Fig. 5a) shows that the cyclones do actually originate over the sea.

Cyclone activity is increased in both areas in category B (Figs. 4b, 5b), particularly so in the western region, where 44 cyclones formed during this category, a daily genesis rate of $\hat{p}=6.4 \%$, which is almost double the average value of $p_{0}=3.7 \%$ (Table 1 ) and is significant at the $95 \%$ level. Again, this is consistent with the MJO basic state, which has enhanced convection over the whole sector in category B (Fig. 3b).

Within category C (Fig. 4c), cyclogenesis is reduced in the western region, and significantly increased (at the $95 \%$ level) in the eastern region such that 20 cyclones form in each region, in contrast to the climatology presented in Fig. 1. This is consistent with the MJO, as convection is enhanced over the eastern region (Fig. 3c).

In category D (Figs. 4d, 5d), the overall TC numbers are strongly reduced over the western region with 12 cyclones or a daily genesis rate of $\hat{p}=1.6 \%$, which is less than half the average rate of $p_{0}=3.7 \%$ (Table 1 ) and is significant at the $95 \%$ level, consistent with the strongly suppressed convection over the sector during this phase of the MJO (Fig. 3d).

Category NONE (Figs. 4e, 5e) can be considered as a control case of cyclone activity when there is no MJO signal to affect the cyclogenesis. In the western region,

\section{$\leftarrow$}

FIG. 5. As in Fig. 4 but for tropical cyclone tracks. Dots are marked at each (typically 6 hourly) point on the track. Cyclones that became severe (intense) with estimated central pressures below $970 \mathrm{hPa}(930$ $\mathrm{hPa}$ ) at some point on their track are shown by dashed lines with pluses (dotted lines with open circles).
TABLE 1. Summary of tropical cyclone formation within each MJO category. Here, $N$ denotes the number of days for which the MJO was in a particular category (this is shown in brackets as a percentage of the total number of days); $N_{\text {WEST }}$ denotes the number of days on which a tropical cyclone formed in the western region (west of $135^{\circ} \mathrm{E}$ ), within that $\mathrm{MJO}$ category (this is shown in brackets as a percentage daily genesis rate, i.e., $100 \times N_{\mathrm{WEST}} / N$ ); and $N_{\mathrm{EAST}}$ is the corresponding statistic for the eastern region (east of $135^{\circ} \mathrm{E}$ ). Categories where TC numbers were significantly above (below) average at the $90 \%$ and $95 \%$ significant levels are indicated by $*$ and $* *(\dagger$ and $\ddagger)$, respectively.

\begin{tabular}{lccc}
\hline \hline $\begin{array}{l}\text { MJO } \\
\text { category }\end{array}$ & $N$ & \multicolumn{1}{c}{$N_{\text {wEST }}$} & \multicolumn{1}{c}{$N_{\text {EAST }}$} \\
\hline A & $675(17.5 \%)$ & $16(2.4 \%) \dagger$ & $7(1.0 \%)$ \\
B & $689(17.8 \%)$ & $44(6.4 \%)^{* *}$ & $15(2.2 \%)$ \\
C & $653(16.9 \%)$ & $20(3.1 \%)$ & $20(3.1 \%)^{* *}$ \\
D & $756(19.6 \%)$ & $12(1.6 \%)$ & $14(1.9 \%)$ \\
NONE & $1092(28.2 \%)$ & $50(4.6 \%)$ & $13(1.2 \%)$ \\
Total & $3865(100 \%)$ & $142(3.7 \%)$ & $70(1.8 \%)$ \\
\hline
\end{tabular}

the genesis locations tend to coincide with the climatological values. High activity is apparent over the Timor Sea, just off the northwestern Australian coast, with another peak farther to the west near $100^{\circ} \mathrm{E}$. The eastern region shows less activity than expected, suggesting that in general, cyclogenesis in the east may be helped by the presence of an MJO. However, activity in both regions in category NONE is not significantly different from the average activity.

The motion of the cyclone tracks (Fig. 5) was examined for differences between the MJO categories. Mean motion vectors of the cyclone tracks were calculated in $5^{\circ} \times 5^{\circ}$ boxes for each category. However, the motion vector fields in all categories were noisy but similar to the climatological motion vector field and there were no significant differences between categories.

The effect of the strength of the MJO on cyclone formation was examined by adjusting the level of the amplitude threshold used to categorize the MJO. Table 2 displays the results obtained from raising the amplitude threshold from 1.0 to 1.2, which eliminates MJOs of only moderate amplitude from the analysis. There are fewer days in categories A-D, and correspondingly more days in the NONE category here. The general pattern of TC modulation is similar to that described above, but the modulation is slightly stronger. If the amplitude threshold is reduced to 0.6 (Table 3 ), the re-

TABLE 2. As in Table 1 except with the running-mean amplitude threshold set at 1.2.

\begin{tabular}{lccc}
\hline \hline $\begin{array}{c}\text { MJO } \\
\text { category }\end{array}$ & $N$ & $N_{\text {wEST }}$ & $N_{\text {EAST }}$ \\
\hline A & $483(12.5 \%)$ & $11(2.3 \%) \dagger$ & $4(0.8 \%)$ \\
B & $543(14.1 \%)$ & $35(6.4 \%)^{* *}$ & $13(2.4 \%)$ \\
$\mathrm{C}$ & $525(13.6 \%)$ & $15(2.9 \%)$ & $17(3.2 \%)^{* *}$ \\
$\mathrm{D}$ & $600(15.5 \%)$ & $10(1.7 \%) \ddagger$ & $15(2.5 \%)$ \\
NONE & $1714(44.4 \%)$ & $71(4.1 \%)$ & $21(1.2 \%) \dagger$ \\
Total & $3865(100 \%)$ & $142(3.7 \%)$ & $70(1.8 \%)$ \\
\hline
\end{tabular}


TABLE 3. As in Table 1 except with running-mean amplitude threshold set at 0.6.

\begin{tabular}{lccc}
\hline \hline $\begin{array}{c}\text { MJO } \\
\text { category }\end{array}$ & $N$ & $N_{\text {wEST }}$ & \multicolumn{1}{c}{$N_{\text {EAST }}$} \\
\hline A & $839(21.7 \%)$ & $23(2.7 \%)$ & $10(1.2 \%)$ \\
B & $797(20.6 \%)$ & $47(5.9 \%)^{* * *}$ & $16(2.0 \%)$ \\
C & $759(19.6 \%)$ & $25(3.3 \%)$ & $20(2.6 \%)^{*}$ \\
D & $837(21.7 \%)$ & $20(2.4 \%)$ & $15(1.8 \%)$ \\
NONE & $633(16.4 \%)$ & $27(4.3 \%)$ & $9(1.4 \%)$ \\
Total & $3865(100 \%)$ & $142(3.7 \%)$ & $70(1.8 \%)$ \\
\hline
\end{tabular}

sults are again consistent with the pattern described above, but with the modulation becoming less pronounced as weaker MJOs are now also retained in the analysis. Only about $16 \%$ of the days are transferred into the NONE category in this case. However, even at this threshold, significant differences remain in both regions, particularly in the west. The initial threshold of 1.0 was rather arbitrary, and Tables 2 and 3 show that the qualitative relationship between the MJO and tropical cyclogenesis is not crucially dependent on the choice of threshold, and it holds for relatively weak, moderate, and strong MJOs.

Some care needs to be exercized in drawing conclusions from observations based on Figs. 4 and 5 and Tables 1-3, particularly when attempting to assign cause and effect. The working hypothesis is that the slowly varying MJO changes the basic state, which then causes a change in TC activity. It could be argued that a chance grouping together of TCs could lead to an enhancement of convection on an intraseasonal timescale. However, by maintaining only an eastward-moving signal through the MJO analysis procedure adopted, the hypothesis that the MJO sets a varying background upon which the cyclones develop is justified.

\section{b. Effect of El Niño}

As discussed in section 1, ENSO has a significant impact on TC activity in the Australian region. It has also been found that the characteristics of the MJO are altered by the phase of ENSO (Hendon et al. 1999). Hence, the analysis was repeated, but only those periods when El Niño conditions were prevalent were included. The Southern Oscillation index (SOI), defined as the normalized station pressure difference between Tahiti and Darwin, was used to define El Niño. Specifically, only those months where the 5-month running mean of the SOI was below -1.0 were included in the analysis.

As the mean convection shifts eastward from the Indonesian region into the central Pacific during an El Niño event, it may have been expected that the proportion of the total number of days in categories $\mathrm{A}$ and B compared to C and D would be reduced. However, the relative proportions are virtually unchanged (Table 4). Consistent with earlier studies (e.g., Broadbridge and Hanstrum 1998; Nicholls 1979), the overall rate of cy-
TABLE 4. As in Table 1 except for El Niño conditions only.

\begin{tabular}{lccc}
\hline \hline $\begin{array}{c}\text { MJO } \\
\text { category }\end{array}$ & $N$ & $N_{\text {wEST }}$ & \multicolumn{1}{c}{$N_{\text {EAST }}$} \\
\hline A & $148(14.1 \%)$ & $0(0.0 \%) \dagger$ & $0(0.0 \%)$ \\
B & $167(15.9 \%)$ & $12(7.2 \%)^{* * *}$ & $3(1.8 \%)$ \\
C & $128(12.2 \%)$ & $2(1.6 \%)$ & $5(3.9 \%)^{* *}$ \\
D & $197(18.7 \%)$ & $0(0.0 \%)$ & $3(1.5 \%)$ \\
NONE & $412(39.2 \%)$ & $10(2.4 \%)$ & $3(0.7 \%)$ \\
Total & $1052(100 \%)$ & $24(2.3 \%)$ & $14(1.3 \%)$ \\
\hline
\end{tabular}

clogenesis is reduced during El Niño conditions, from $3.7 \%$ to $2.3 \%$ in the western region and from $1.8 \%$ to $1.3 \%$ in the eastern region (Tables 1 and 4). Furthermore, the reductions in the western and eastern regions appear to be of a similar magnitude.

Within the categories themselves, there is evidence of increased modulation of TC activity by the MJO when only El Niño periods were included. For example, in category A no TCs were observed to form in either region. In the western region, this represented a significant departure (at the 90\% level) from the full-time domain case. In category $\mathrm{B}$, the cyclogenesis rate of $\hat{p}$ $=7.2 \%$ in the western region is triple the "climatological" El Niño value of $p_{0}=2.3 \%$. In category $\mathrm{C}$, the cyclogenesis rate of $\hat{p}=3.9 \%$ in the eastern region is triple the climatological value of $p_{0}=1.3 \%$, and in category $\mathrm{D}$, there are no tropical cyclones in the western region.

\section{Tropical cyclogenesis parameters}

\section{a. Introduction}

Several studies have documented the large-scale conditions associated with tropical cyclogenesis. For example, Gray $(1968,1975)$ isolated six necessary thermodynamic and dynamic conditions that needed to be satisfied for TC formation to occur, and showed how these parameters could be used to reproduce the observed large-scale patterns of TC formation around the globe. This work and subsequent studies (e.g., McBride and Zehr 1981; Zehr 1992) further showed that the thermodynamic conditions are continuously satisfied for long periods of the year, and it is the dynamical parameters that have the major effect on cyclogenesis rates. In particular, the most important discriminator between pre-tropical cyclone and nondeveloping disturbances is the low-level relative vorticity of the environment, with cyclonic vorticity being favorable for cyclogenesis. Although high values of vertical wind shear are well known to be an inhibitor of tropical cyclogenesis, Zehr (1992) has shown there to be little evidence of vertical wind shear having an effect on climatological cyclogenesis rates, and McBride and Zehr (1981) found that low-level relative vorticity was a much better discriminator than vertical wind shear. 


\section{b. Low-level relative vorticity}

MJO-induced perturbations of the large-scale dynamical genesis parameters away from the climatological background were first examined by constructing regression maps of low-level relative vorticity for the different phases of the MJO. Maps of anomalous 850-hPa relative vorticity for each MJO category are shown in Fig. 6. As the domain is in the Southern Hemisphere, negative relative vorticity anomalies (dark shading) are cyclonic and indicate the favorable areas for cyclogenesis. There is a close correspondence between these large-scale cyclonic anomalies and the regions of enhanced cyclogenesis described in section 3. In category $\mathrm{A}$, there is a large area of strongly enhanced cyclonic vorticity to the south of Sumatra (Fig. 6a), in agreement with the observed shift in cyclone formation to this area during this category (Fig. 4a).

During category $\mathrm{B}$, in which the maximum TC activity occurs in both western and eastern regions, the area of enhanced cyclonic vorticity has moved eastward, to cover the north of Australia. The steady reduction in activity in categories $\mathrm{C}$ and $\mathrm{D}$ is also consistent with the low-level vorticity anomalies, as an anticyclonic vorticity anomaly replaces the cyclonic anomaly from the west.

Once again, caution needs to be exercized here in assigning cause and effect to these observations. For example, it could be argued that it is the increased number of TCs in category B, rather than the large-scale MJO circulation itself, that is responsible for the observed cyclonic relative vorticity anomaly in Fig. 6b. However, observational and modeling studies have shown that the low-level cyclonic vorticity anomaly arises as an equatorial Rossby wave response to the anomalous MJO convective heating over Indonesia (Hendon and Salby 1994; Matthews et al. 1999; Matthews 2000).

\section{c. Daily genesis parameter}

Empirical genesis parameters have been defined to relate the necessary large-scale conditions for cyclogenesis to observed TC formation (Gray 1975; McBride and Zehr 1981; Zehr 1992). These parameters represent observed cyclogenesis rates well. McBride and Zehr (1981) proposed a daily genesis parameter (DGP) based on observations that cyclogenesis is particularly favored in areas of cyclonic low-level vorticity and zero vertical wind shear with large positive vertical shear of the zonal wind to the south and large negative vertical shear to the north. ${ }^{1}$ The DGP is then simply the negative of the vertical vorticity shear:

$$
\mathrm{DGP}=\zeta_{850}-\zeta_{200},
$$

${ }^{1}$ This result has been adapted from McBride and Zehr (1981) for the Southern Hemisphere case considered here.

\section{(a) Category $\mathrm{A}$}

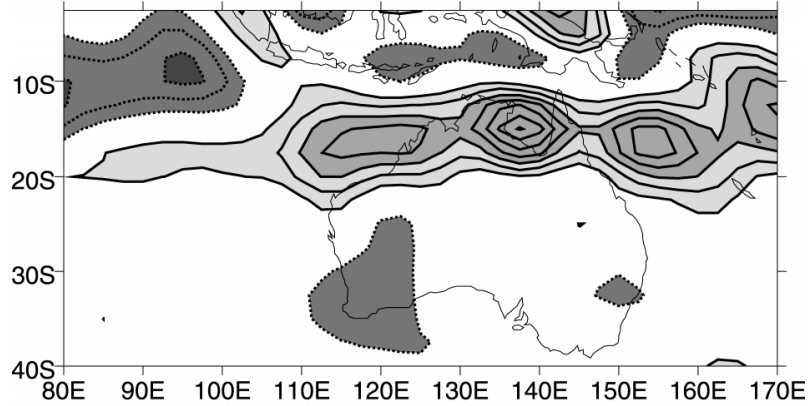

(b) Category $\mathrm{B}$

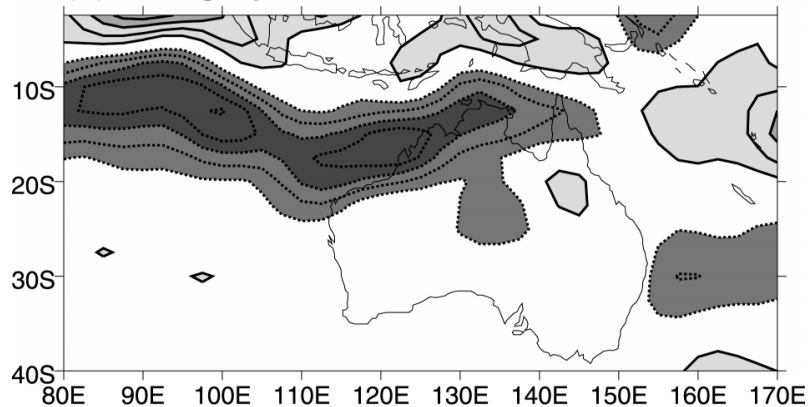

(c) Category C

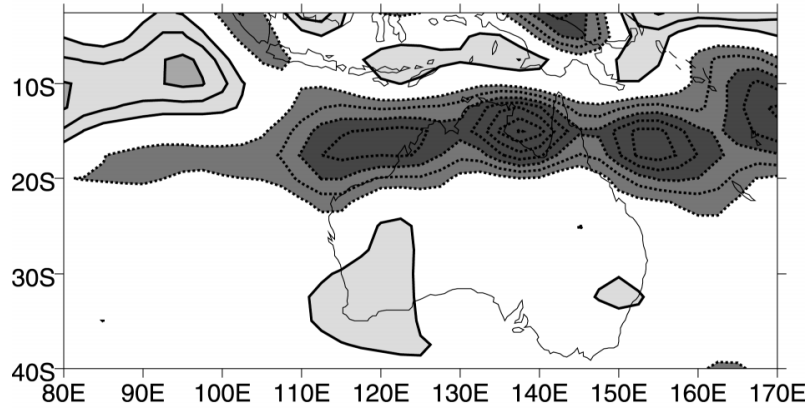

(d) Category D

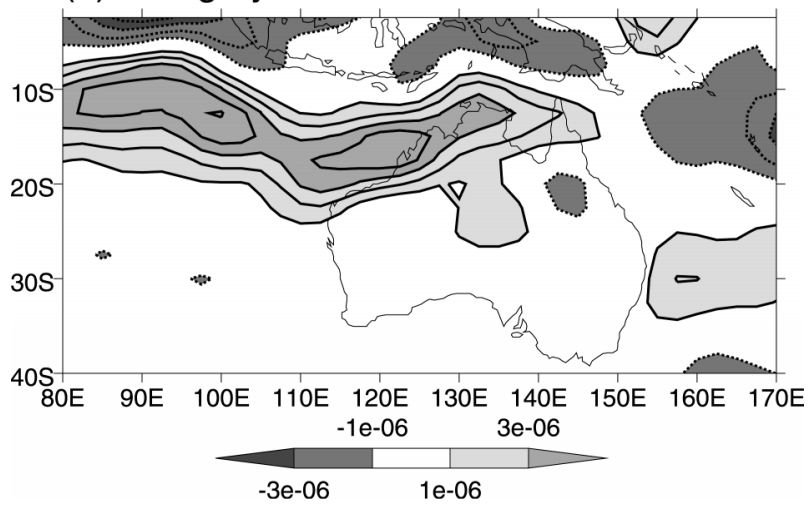

FIG. 6. As in Fig. 3 but for $850-\mathrm{hPa}$ vorticity. Contour interval is $1 \times 10^{-6} \mathrm{~s}^{-1}$; negative contours are dotted and the zero contour is omitted. Shading is indicated by the legend.

where $\zeta_{850}$ and $\zeta_{200}$ are the vorticity at 850 and $200 \mathrm{hPa}$, respectively (McBride and Zehr used vorticity at the 900-hPa level rather than at $850 \mathrm{hPa}$ ). They found that the DGP was markedly more negative for developing 
as opposed to nondeveloping systems. Although this parameter was designed for the investigation of individual systems, it was felt that over the 10-12-day timescale of an MJO category, the DGP would reflect the necessary conditions for cyclogenesis. The DGP anomalies in each MJO category (Fig. 7) show a broadly similar pattern to the corresponding anomalies in 850hPa vorticity (Fig. 6), as the upper- and lower-level MJO vorticity anomalies tend to be of opposite sign, due to the baroclinic nature of the equatorial wave response to the MJO convective heating.

However, the DGP anomalies over the Australian region are shifted southward relative to their corresponding $850-\mathrm{hPa}$ vorticity anomalies. For example, in category $\mathrm{C}$ the 850 -hPa vorticity minimum lies along $18^{\circ} \mathrm{S}$ (Fig. 6c), while the DGP anomaly is a minimum along $25^{\circ} \mathrm{S}$ (Fig. 7c). This southward shift of the DGP anomaly is due to the $200-\mathrm{hPa}$ vorticity anomaly, which has an anticyclonic maximum along $27^{\circ} \mathrm{S}$ (not shown), associated with the upper-tropospheric anticyclonic response to the MJO heating over the western Pacific. However, the DGP anomaly is still (weakly) negative along $18^{\circ} \mathrm{S}$ (Fig. 7c) in category $\mathrm{C}$, in the region of negative 850 hPa vorticity anomaly (Fig. 6c) and enhanced tropical cyclone activity over the eastern region (Fig. 4c; Table 1 ). Therefore, although the DGP anomalies are consistent with the changes to tropical cyclone activity, they do not appear to be as good a predictor as $850-\mathrm{hPa}$ vorticity.

A similar analysis was also carried out for the vertical shear of the zonal wind between 200 and $850 \mathrm{hPa}$ (not shown). It was found that the climatological mean wind shears completely dominated the MJO-induced anomalies unlike in the case of vorticity. Using a similar technique for the northeastern Pacific case, Maloney and Hartmann (2000) found that the line of zero vertical shear was located over the main cyclogenesis area during the active phase of the MJO, but moved to the south during the passive phase. This was not the case for the Australian region in this study; the zero line was located over the peak cyclogenesis areas for all phases of the MJO. However, in light of the apparent lack of influence of vertical wind shear over large-scale cyclogenesis rates, this may not be important.

\section{Discussion and conclusions}

The observed relationship between tropical cyclones in the Australian region and the MJO has been investigated by dividing the MJO cycle into four categories (A-D), with a fifth category (NONE) defined for those times when no MJO signal was present. Significant differences were found in the amount of TC activity between the categories. These differences were particularly pronounced in the western region in category B with greatly enhanced cyclogenesis (and in category D with reduced activity) when there is enhanced (or reduced) MJO convection over the Australian sector, re- (a) Category A

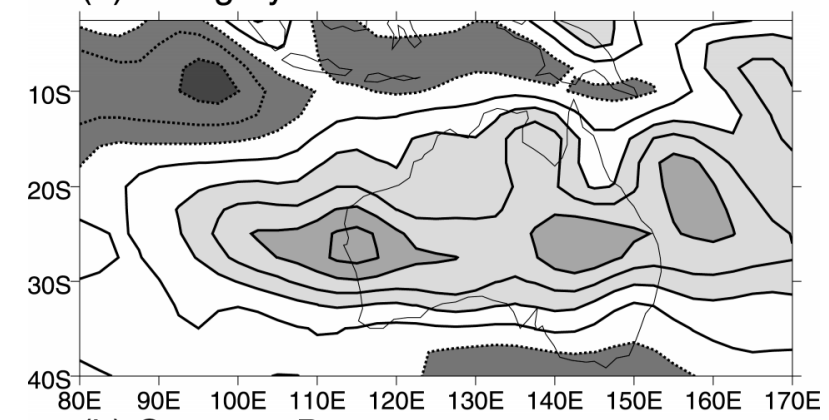

(b) Category B
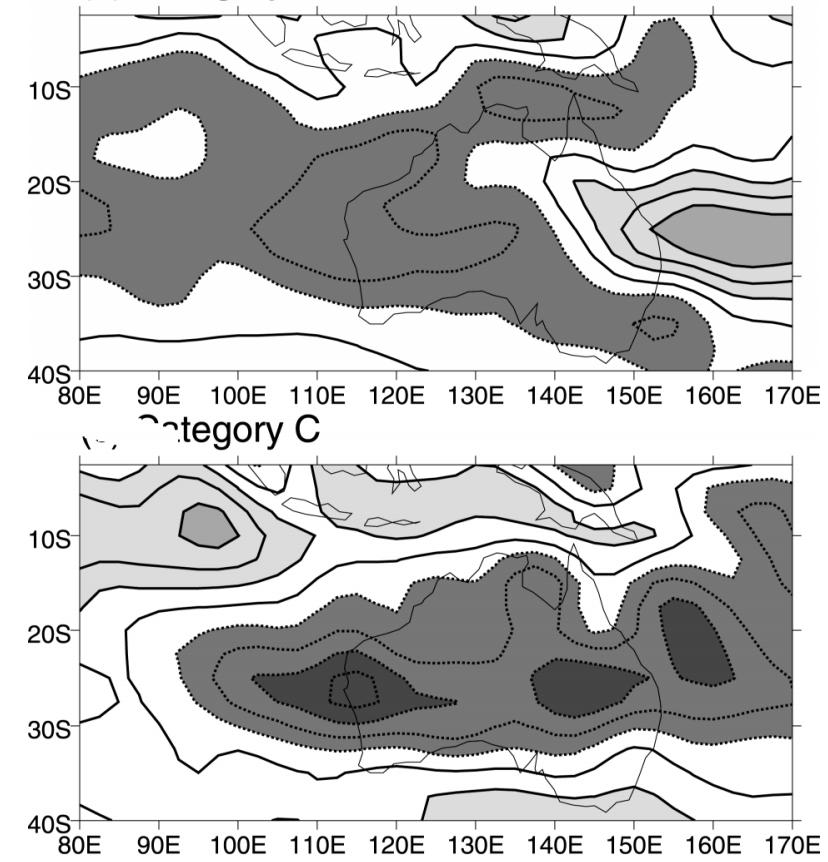

(d) Category D

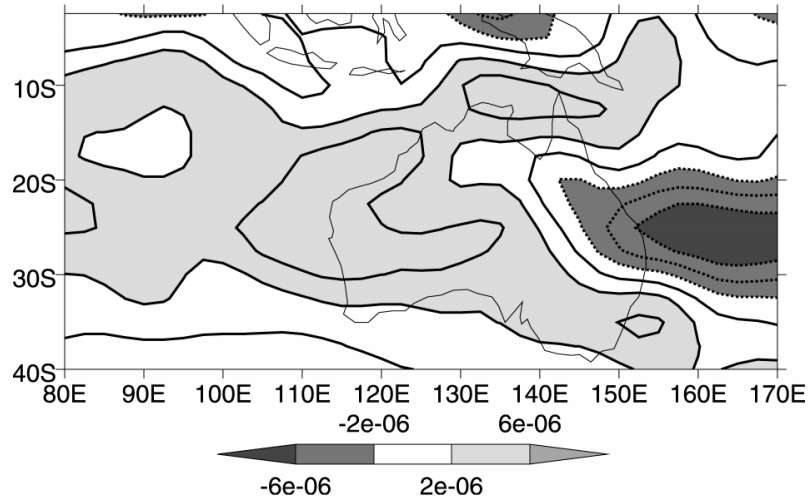

FIG. 7. As in Fig. 3 but for the DGP. Contour interval is $2 \times 10^{-6}$ $\mathrm{s}^{-1}$; negative contours are dotted. Shading is indicated by the legend.

spectively. In category $\mathrm{C}$, there was significantly enhanced TC activity over the eastern region corresponding to enhanced MJO convection over this sector. When only strong MJOs are considered, the modulation of cyclogenesis increases in both the western and eastern 
regions, which is indicative of a strong relationship between the MJO and TC activity. When only El Niño periods were included, the relationship between the MJO and TC activity strengthened further.

During periods with no MJO signal (category NONE), tropical cyclones still formed at or slightly above the climatological rate in the western region, but below the climatological rate in the eastern region. A possible explanation for these observations is the origin of the precyclone cloud clusters. In the east, they are almost exclusively produced within the ITCZ, upon which the MJO has a strong modulation. In the west, the majority of the cloud clusters also form in the ITCZ, but there is a significant fraction of precyclone cloud clusters, some $10 \%-15 \%$, that originate as heat lows over the Kimberley or Pilbara regions of the mainland, and develop once they move offshore. This mechanism may be less affected by the MJO than the more usual ITCZ formation. The observed cyclone tracks (Fig. 5) tend to support this notion, as it is apparent from these that cyclogenesis occurs close to the western Australian coast, irrespective of the MJO category.

The modulation of other tropical cyclone characteristics by the MJO was also examined. In particular, the number of severe tropical cyclones in each category was determined. Tropical cyclones were defined as severe if their estimated central pressure fell below $970 \mathrm{hPa}$, which approximately corresponds to the transition from tropical storm to typhoon or hurricane. The number of severe tropical cyclones was above average in the western region during category $\mathrm{B}$ of the $\mathrm{MJO}$, but none of these results were statistically significant. Vector velocities for the motion of each cyclone center were also calculated. However, there were no statistically significant changes in these motion vectors between the MJO categories.

The increase in meso- and synoptic-scale convective activity in the enhanced convective phase of the MJO is undoubtedly important to the modulation of cyclogenesis (Liebmann et al. 1994). However, changes to the large-scale parameters necessary for cyclogenesis during the MJO cycle are also important in the Australian region. In particular, areas of enhanced TC formation coincided with regions of enhanced low-level vorticity and increased daily genesis parameters (vertical shear of vorticity) associated with the equatorial Rossby wave response to the MJO convective anomaly.

Maps of the cyclone genesis parameters such as those in Figs. 6 and 7 may be useful in a prognostic sense, and may provide medium-range guidance to TC activity, although the methodology would have to be adapted to use real-time, unfiltered data. At the present time, numerical weather prediction models show little skill in forecasting the MJO beyond lead times of a few days. However, this situation may change in the near future. Statistical methods have had some success in predicting the future evolution of the MJO out to lead times of 2 to 3 weeks (Waliser et al. 1999; Lo and Hendon 2000;
Wheeler and Weickmann 2001). The evidence suggests that statistical predictions of the MJO are at a stage now where they could be used to improve medium-range tropical cyclone forecasting in the Australian region.

Acknowledgments. The best track tropical cyclone data and the SOI data were provided by the Australian Bureau of Meteorology, and quality controlled by Jon Gill. The NOAA Climate Diagnostics Center (http:// www.cdc.noaa.gov) provided the NCEP-NCAR reanalysis and OLR data. This research was partly carried out at the Cooperative Research Centre for Southern Hemisphere Meteorology and was supported in part through the Australian Government Cooperative Research Centres Program. The authors thank the three anonymous reviewers, whose comments helped to improve the manuscript.

\section{REFERENCES}

Broadbridge, L. W., and B. N. Hanstrum, 1998: The relationship between tropical cyclones near Western Australia and the Southern Oscillation index. Aust. Meteor. Mag., 47, 183-190.

Davidson, N. E., and H. C. Weber, 2000: The BMRC High-Resolution Tropical Cyclone Prediction System: TC-LAPS. Mon. Wea. Rev., 128, $1245-1265$.

Dvorak, V. F., 1984: Tropical cyclone intensity analysis using satellite data. NOAA Tech. Rep. NESDIS 11, $47 \mathrm{pp}$.

Evans, J. L., and R. J. Allan, 1992: El Niño/Southern Oscillation modification to the structure of the monsoon and tropical cyclone activity in the Australasian region. Int. J. Climatol., 12, 611623.

Frank, W. M., 1982: Large-scale characteristics of tropical cyclones. Mon. Wea. Rev., 110, 572-586.

Gray, W. M., 1968: Global view of the origin of tropical disturbances and storms. Mon. Wea. Rev., 96, 669-700.

_ 1975: Tropical cyclone genesis. Dept. of Atmospheric Sciences Paper 232, Colorado State University, Fort Collins, CO, 121 pp. , 1979: Hurricanes: Their formation, structure and likely role in the tropical circulation. Meteorology over the Tropical Oceans, D. B. Shaw, Ed., Royal Meteorological Society, 155-218.

—_, and J. D. Sheaffer, 1989: El Niño and QBO influences on tropical cyclone activity. Teleconnections Linking Worldwide Climate Anomalies, M. H. Glantz, R. W. Katz, and N. Nicholls, Eds., Cambridge University Press, 257-284.

—_ C. W. Landsea, P. W. Mielke Jr., and K. J. Berry, 1992: Predicting Atlantic seasonal hurricane activity 6-11 months in advance. Wea. Forecasting, 7, 440-455.

,,--- , and -1993 : Predicting Atlantic basin tropical cyclone activity by 1 August. Wea. Forecasting, 8, 73-86.

Hanstrum, B. N., G. Reader, and P. W. Bate, 1999: The South Pacific and southeast Indian Ocean tropical cyclone season 1996-7. Aust. Meteor. Mag., 48, 197-210.

Hendon, H. H., and B. Liebmann, 1994: Organisation of convection within the Madden-Julian oscillation. J. Geophys. Res., 99, 8073-8083.

_- and M. L. Salby, 1994: The life cycle of the Madden-Julian oscillation. J. Atmos. Sci., 51, 2225-2237.

, C. Zhang, and J. D. Glick, 1999: Interannual variation of the Madden-Julian oscillation during austral summer. J. Climate, $12,2538-2550$.

Holland, G. J., 1984: On the climatology and structure of tropical cyclones in the Australian/southwest Pacific region: I. Data and tropical storms. Aust. Meteor. Mag., 32, 1-15.

Kalnay, E., and Coauthors, 1996: The NCEP/NCAR 40-Year Reanalysis Project. Bull. Amer. Meteor. Soc., 77, 437-471. 
Landsea, C. W., W. M. Gray, P. W. Mielke Jr., and K. J. Berry, 1994: Seasonal forecasting of Atlantic hurricane activity. Weather, 49, 273-284.

Liebmann, B., and C. A. Smith, 1996: Description of a complete (interpolated) OLR dataset. Bull. Amer. Meteor. Soc., 77, 12751277.

- H. H. Hendon, and J. D. Glick, 1994: The relationship between tropical cyclones of the western Pacific and Indian Oceans and the Madden-Julian oscillation. J. Meteor. Soc. Japan, 72, 401411.

Lo, F., and H. H. Hendon, 2000: Empirical extended-range prediction of the Madden-Julian oscillation. Mon. Wea. Rev., 128, 25282543.

Madden, R. A., and P. R. Julian, 1994: Observations of the 40-50day tropical oscillation-A review. Mon. Wea. Rev., 122, 814 837.

Maloney, E. D., and D. L. Hartmann, 2000: Modulation of eastern North Pacific hurricanes by the Madden-Julian oscillation. $J$. Climate, 13, 1451-1460.

Matthews, A. J., 2000: Propagation mechanisms for the MaddenJulian oscillation. Quart. J. Roy. Meteor. Soc., 126, 2637-2652.

— , B. J. Hoskins, J. M. Slingo, and M. Blackburn, 1996: Development of convection along the SPCZ within a Madden-Julian oscillation. Quart. J. Roy. Meteor. Soc., 122, 669-688.

— slow Kelvin waves in the Madden-Julian oscillation of a GCM Quart. J. Roy. Meteor. Soc., 125, 1473-1498.

McBride, J. L., and R. Zehr, 1981: Observational analysis of tropical cyclone formation. Part II: Comparison of non-developing versus developing systems. J. Atmos. Sci., 38, 1132-1151.

- , and T. D. Keenan, 1982: Climatology of tropical cyclone genesis in the Australian region. J. Climatol., 2, 13-33.

Nakazawa, T., 1988: Tropical super clusters within intraseasonal variations over the western Pacific. J. Meteor. Soc. Japan, 66, 823839.

Nicholls, N., 1979: A possible method for predicting seasonal tropical cyclone activity in the Australian region. Mon. Wea. Rev., 107, 1221-1224.

Solow, A., and N. Nicholls, 1990: The relationship between the Southern Oscillation and tropical cyclone frequency in the Australian region. J. Climate, 3, 1097-1101.

von Storch, H., and A. Smallegange, 1991: The phase of the 30- to 60-day oscillation and the genesis of tropical cyclones in the western Pacific. Max-Planck-Institut für Meteorologie Rep. 66, 22 pp.

Waliser, D. E., C. Jones, J.-K. E. Schemm, and N. E. Graham, 1999: A statistical extended-range tropical forecast model based on the slow evolution of the Madden-Julian oscillation. J. Climate, 12, 1918-1939.

Wheeler, M., and K. M. Weickmann, 2001: Real-time monitoring and prediction of modes of coherent synoptic to intraseasonal tropical variability. Mon. Wea. Rev., 129, 2677-2694.

Zehr, R. M., 1992: Tropical cyclogenesis in the western North Pacific. NOAA Tech. Rep. NESDIS 61, 181 pp. [Available from U.S. Department of Commerce, NOAA/NESDIS, 5200 Auth Rd., Washington, DC 20233.] 